\title{
Optimization of lovastatin production by Fusarium nectrioides (MH173849) using response surface methodology and fuzzy logic system
}

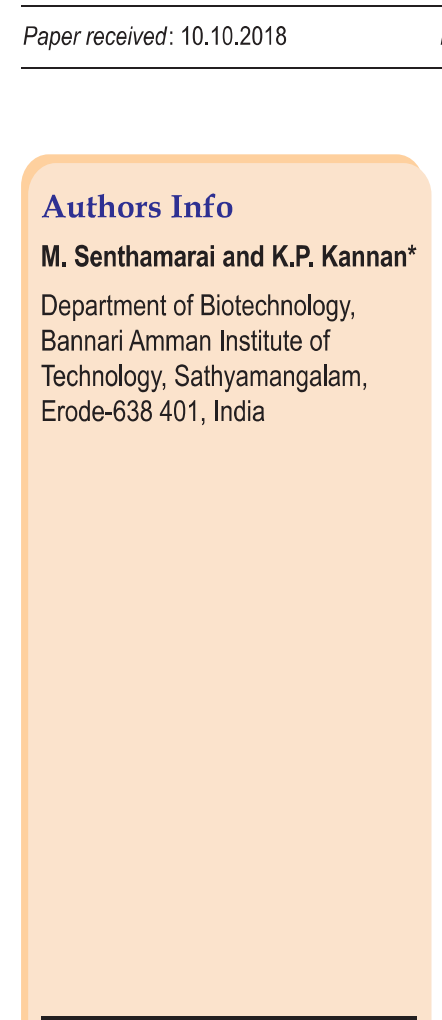

*Corresponding Author Email : drkpkannan@gmail.com

\section{Edited by \\ Dr. T.K. Ghosh}

Reviewed by Dr. Muthu Kumar Manoharan Dr. Sumitha
Revised received: 29.11 .2018

Re-revised received: 04.01.2019

Accepted: 22.04 .2019

\section{Abstract}

Aim : To enhance the productivity of lovastatin from Fusarium nectrioides isolate with liquid cheese whey as a major carbon source and to optimize the media components using Response Surface Methodology (RSM) and Fuzzy Logic System (FLS).

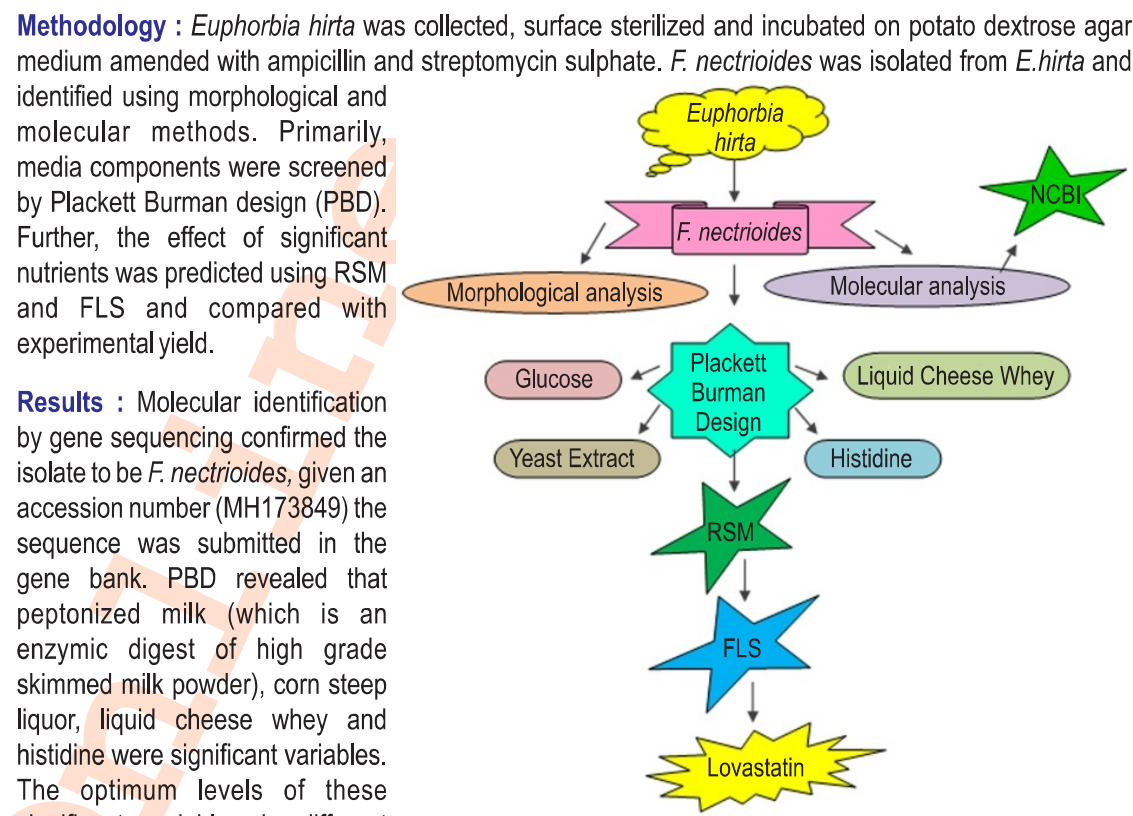
significant variables in different combinations were studied by RSM in which the predicted yield of lovastatin was $1.2 \mathrm{gl}^{-1}$. Further, it was analyzed by FLS with 14 set of fuzzy rules and the maximum production obtained was $1.8 \mathrm{~g}^{100 \mathrm{ml}^{-1}}$ which

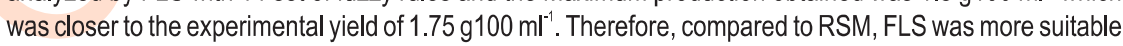
technique to determine the optimum levels of significant nutrients for enhanced lovastatin production.

Interpretation : This study suggests that $F$. nectrioides (MH173849) can be used as a potent producer of lovastatin and the production highly influenced by glucose, corn steep liquor, liquid cheese whey and histidine.

Key words: Cheese Liquid whey, Euphorbia hirta, Fusarium nectrioides, Fuzzy Logic system, Lovastatin

How to cite : Senthamarai, M. and K.P. Kannan: Optimization of lovastatin production by Fusarium nectrioides (MH173849) using response surface methodology and fuzzy logic system. J. Environ. Biol., 40, 1036-1044 (2019). DOI : http://doi.org/10.22438/jeb/40/5/MRN-1016 


\section{Introduction}

Lovastatin is a potent anti-cholesterol compound and competitive inhibitor of 3 hydroxyl 3 methylglutaryl co-enzyme A reductase (HMG-CoA) which has a huge demand in the pharmaceutical and health sectors (Tandon et al., 2005; Alberts et al., 1980). It is also used to prevent stroke, reduce the development of peripheral vascular disease and treat bone fractures (Pahan, 2006). Due to its pleiotropic effects (Davies et al., 2016), it has received increasing recognition and clinical applicability across a broad range of cardiovascular and noncardiovascular conditions, including Alzheimer's, cancer, dementia, Parkinson's, multiple sclerosis and rheumatoid arthritis (Davignon and Leiter, 2005). Owing to its significant importance in medicinal field, the cost effective production of lovastatin in large scale is highly solicited. Therefore, industries are seeking assistance of strong scientific technology and statistical tools for enhancing the production of Lovastatin (Seenivasan et al., 2008).

Lovastatin is a secondary metabolite produced during the exponential phase of selective endophytic fungi under optimal conditions. Isolating a potential endophytic fungi and designing a fermentation medium is crucial for the enhanced production of lovastatin (Hutchinson et al., 2000; Goswami et al., 2012). Lovastatin is produced from multiple genera and types of filamentous fungi, including Aspergillus, Penicillium, Monascus, Paecilomyces, Trichoderma, Scopolariopsis, Doratomyces, Phoma, Phythium, Gymnoascus, Hypomyces and Pleurotus (Casas López et al., 2003). Endophytic fungi from medicinal plants have gained greater attention due to their rich diversity (Pinruan et al., 2010) towards the production of secondary metabolites. The concentration of biomass and production of lovastatin mainly depends on selection of carbon sources (Dhar and Nigam, 2015; Gonciarz et al., 2016; Boruta et al., 2017).

Liquid cheese whey is a yellowish liquid, remaining after milk coagulation during cheese production. It is a valuable byproduct of cheese industry and has huge commercial applications due its high lactose content and milk nutrients (Lievore et al., 2015). Although several efforts have been employed for the utilization of cheese-whey, almost half of its global production is left untreated and is discarded as an effluent (Wang et al., 2017). Hence, in this study, liquid cheese whey has been used as a carbon source in addition to glucose for the growth of fungal species, Fusarium nectrioides and significant nutrients have been optimized using RSM and FLS.

\section{Materials and Methods}

Collection of weed plants and surface sterilization of leaves: Healthy and matured leaves of a pantropical weed, Euphorbia hirta, were collected from in and around Sathyamangalam region, Erode district, Tamil Nadu. Samples were collected in a sterile ziplock bag and processed within 24 hrs at the Endophytic Fungal Research Laboratory, Bannari Amman Institute of Technology. Authentication of plant specimen was done at Botanical Survey of
India, Tamil Nadu Agriculture University, Coimbatore. Fresh and healthy leaves of weed plants were washed thoroughly with sterile water to remove soil and debris from the leaf surface. The surface sterile leaves were cut into 50 small segments of $0.5 \mathrm{~cm} x$ $0.5 \mathrm{~cm}$ using sterile scalpel and placed equidistantly on the freshly prepared Potato Dextrose Agar plates (PDA) amended with ampicillin $\left(50 \mathrm{\mu gm}^{-1}\right)$ and streptomycin sulphate $\left(250 \mu \mathrm{g} \mathrm{m}^{-1}\right)$. The segments inoculated in PDA plates were incubated in fungal rack at $25^{\circ} \mathrm{C} \pm 1^{\circ} \mathrm{C}$ provided with $12 \mathrm{hr}$ of light followed by $12 \mathrm{hr}$ of dark cycles till the colony appeared (Dobranic et al., 1995).

Isolation and identification of endophytic fungi : Individual colonies were isolated and subcultured subsequently to obtain pure culture. Endophytic fungi, $F$. nectrioides was isolated and confirmed through morphological and molecular analysis (White et al., 1990) with forward primer (ITS-1F) TCCGTAGGTGA ACCTGCGG and reverse primer (ITS-4R) TCCTCCGCTT ATTGATATGC. The gene sequence of the same was submitted in gene bank to obtain accession number. Stock culture of $F$. nectrioides was maintained on PDA incubated at $28^{\circ} \mathrm{C}$ for 7 days and stored under refrigeration at $5-10^{\circ} \mathrm{C}$.

\section{Growth media and culture conditions}

Seed medium: Spore suspension of $F$. nectrioides (MH173849) was inoculated in the seed media containing Glucose, Liquid cheese whey, Yeast extract, Magnesium sulphate at pH 6. The flask was incubated at $28^{\circ} \mathrm{C}$ for $40 \mathrm{hrs}$ in a shaking incubator at 180 rpm (Samiee et al., 2003; Su et al., 2003).

Production medium: Grown seed culture $\left(5 \times 10^{7}\right.$ spore $\left.\mathrm{ml}^{-1}\right)$ was transferred into the production medium comprising Glucose, Yeast extract, Potassium Di hydrogen Phosphate, Peptonized milk, Magnesium sulphate, Histidine, Liquid cheese whey, at pH 6 in triplicates. All the flasks were incubated in shaker incubator at $28^{\circ} \mathrm{C}$ and $180 \mathrm{rpm}$ for 15 days (Karthika et al., 2013; Hajjaj et al., 2001; Casas lopez et al., 2003).

Extraction of lovastatin: After 12 days of fermentation, the culture broth was separated by filtration using sterilized filter cloth. The culture filtrate was adjusted from $\mathrm{pH} 6$ to $\mathrm{pH} 2$ and kept in a rotatory shaker with equal volume of ethyl acetate at $100 \mathrm{rpm}$ for $2 \mathrm{hrs}$ in room temperature. After the extraction process, the broth was separated from ethyl acetate using separating funnel and concentrated to $20 \mathrm{ml}$ using rotatory evaporator. The presence of Lovastatin in the fermentation broth was confirmed by UV spectrometry at $238 \mathrm{~nm}$. The extract obtained from the culture was analyzed using HPLC with $\mathrm{C} 18$ column as a stationary phase and acetonitrile and water $(65: 35 \mathrm{v} / \mathrm{v})$ as mobile phase. An isocratic condition was maintained in the mobile phase.

The extract was filtered through $0.45 \mu \mathrm{m}$ Millex-LH filter (Millipor corp., Bedford, MA 01730) and a clear extract (20 $\mu$ l) was analyzed using high pressure liquid chromatography (Friedrich et al., 1995; Kysilka and Kren, 1993). The flow rate was maintained as $0.8 \mathrm{~m} \mathrm{~min}^{-1}$ throughout the run and detection was carried out at 
$238 \mathrm{~nm}$. This was further compared with the retention time (5.124 min) of standard lovastatin.

Media optimization for batch fermentation of lovastatin: One factor at a time technique has short comings in locating the region of optimum response in the media optimization. To overcome this issue, Plackett Burman Experimental Design (PBD) is used to screen significant media nutrients (Plackett and Burman, 1946). This technique analyzes the impact of nine assigned factors such as glucose, yeast extract, peptonized milk, soya flour, potassium dihydrogen phosphate, magnesium sulphate, histidine, liquid cheese whey, corn steep liquor and two dummy variables such as

Table 1: High and low levels of factors used in Plackett-Burman Design

\begin{tabular}{llll}
\hline Code & Factors & Low level $(-1)$ & High level $(+1)$ \\
\hline A & Glucose & 15 & 100 \\
B & Yeast extract & 25 & 30 \\
C & Peptonized milk & 15 & 28 \\
D & Soya flour & 3 & 5.8 \\
E & Potassium Di hydrogen Phosphate & 0.3 & 2 \\
F & Magnesium sulphate & 0.05 & 0.8 \\
G & Ferrous sulfate heptahydrate (DV1) & 0.04 & 0.2 \\
H & Histidine & 4 & 7 \\
I & Calcium chloride (DV2) & 0.04 & 0.2 \\
J & Liquid cheese whey & 10 & 25 \\
K & Corn steep liquor & 3 & 5 \\
\hline
\end{tabular}

Table 2 : Twelve runs-Plackett-Burman design matrix for nine variables with coded values

\begin{tabular}{|c|c|c|c|c|c|c|c|c|c|c|c|}
\hline \multicolumn{12}{|c|}{ Media Components ( $\mathrm{g} \mathrm{I}^{-1}$ ) } \\
\hline Run & A & B & C & D & E & $\mathrm{F}$ & G & $\mathrm{H}$ & I & $J$ & K \\
\hline 1. & 100 & 30 & 28 & 5.8 & 2 & 0.05 & 0.04 & 4 & 0.04 & 25 & 3 \\
\hline 2. & 15 & 30 & 28 & 3 & 2 & 0.8 & 0.2 & 4 & 0.04 & 10 & 5 \\
\hline 3. & 100 & 25 & 28 & 5.8 & 0.3 & 0.8 & 0.2 & 7 & 0.04 & 10 & 3 \\
\hline 4. & 15 & 30 & 15 & 5.8 & 2 & 0.05 & 0.2 & 7 & 0.2 & 10 & 3 \\
\hline 5. & 15 & 25 & 28 & 3 & 2 & 0.8 & 0.04 & 7 & 0.2 & 25 & 3 \\
\hline 6. & 15 & 25 & 28 & 5.8 & 0.3 & 0.05 & 0.2 & 4 & 0.2 & 25 & 5 \\
\hline 7. & 100 & 25 & 15 & 3 & 2 & 0.05 & 0.2 & 7 & 0.04 & 25 & 5 \\
\hline 8. & 100 & 30 & 28 & 3 & 0.3 & 0.05 & 0.04 & 7 & 0.2 & 10 & 3 \\
\hline 9. & 100 & 30 & 15 & 3 & 0.3 & 0.8 & 0.2 & 4 & 0.2 & 25 & 3 \\
\hline 10. & 15 & 30 & 15 & 5.8 & 0.3 & 0.8 & 0.04 & 7 & 0.04 & 25 & 5 \\
\hline 11. & 100 & 25 & 15 & 5.8 & 2 & 0.8 & 0.04 & 4 & 0.2 & 10 & 5 \\
\hline 12. & 15 & 25 & 15 & 3 & 0.3 & 0.05 & 0.04 & 4 & 0.04 & 10 & 5 \\
\hline
\end{tabular}

Table 3 : Fourteen set of FUZZY rule and their crispy outputs

\begin{tabular}{|c|c|}
\hline 1. & If(GLU is $\mathrm{L})$ and (YE is HH) and (HIS HHH) and (LCW is LLLL) then (Productivity is LESS) \\
\hline 2. & If(GLU is $\mathrm{L}$ ) and (YE is LL) and (HIS HHH) and (LCW is HHHH) then (Productivity is LESS) \\
\hline 3. & If(GLU is $\mathrm{L})$ and (YE is LL) and (HIS LLL) and (LCW is HHHH) then (Productivity is LESS) \\
\hline 4. & If(GLU is $\mathrm{L})$ and (YE is $\mathrm{HH})$ and (HIS HHH) and (LCW is HHHH) then (Productivity is MEDIUM) \\
\hline 5. & If(GLU is L) and (YE is LL) and (HIS LLL) and (LCW is LLLL) then (Productivity is LESS) \\
\hline 6. & If(GLU is L) and (YE is HH) and (HIS LLL) and (LCW is LLLL) then (Productivity is LESS) \\
\hline 7. & If(GLU is H) and (YE is LL) and (HIS LLL) and (LCW is LLLL) then (Productivity is MEDIUM) \\
\hline 8. & If(GLU is $\mathrm{H})$ and (YE is HH) and (HIS HHH) and (LCW is LLLL) then (Productivity is MEDIUM) \\
\hline 9. & If(GLU is $\mathrm{H})$ and (YE is LL) and (HIS HHH) and (LCW is LLLL) then (Productivity is MEDIUM) \\
\hline 10. & If(GLU is $\mathrm{H})$ and (YE is LL) and (HIS LLL) and (LCW is HHHH) then (Productivity is $\mathrm{HIGH}$ ) \\
\hline 11. & If(GLU is M) and (YE is LL) and (HIS LLL) and (LCW is HHHH) then (Productivity is HIGH) \\
\hline 12. & If(GLU is H) and (YE is HH) and (HIS MMM) and (LCW is LLLL) then (Productivity is MEDIUM) \\
\hline 13. & If(GLU is $\mathrm{H})$ and (YE is MM) and (HIS MMM) and (LCW is HHHH) then (Productivity is MEDIUM) \\
\hline 14. & If(GLU is M) and (YE is LL) and (HIS MMM) and (LCW is MMMM) then (Productivity is MEDIUM) \\
\hline
\end{tabular}


Table 4 : Twelve runs -Plackett-Burman design matrix for nine variables with coded values along with the yield

\begin{tabular}{|c|c|c|c|c|c|c|c|c|c|c|}
\hline \multirow[b]{2}{*}{ Run } & \multicolumn{9}{|c|}{ Media components $\left(\mathrm{gl}^{-1}\right)$} & \multirow{2}{*}{$\begin{array}{l}\text { Yield } \\
\left(\mathrm{g} 100 \mathrm{~m} \mathrm{l}^{-1}\right)\end{array}$} \\
\hline & A & B & C & D & E & $F$ & $\mathrm{H}$ & $J$ & K & \\
\hline 1 & 100 & 30 & 28 & 5.8 & 2 & 0.05 & 4 & 25 & 3 & 1.7 \\
\hline 2 & 15 & 30 & 28 & 3 & 2 & 0.8 & 4 & 10 & 5 & 0.8 \\
\hline 3 & 100 & 25 & 28 & 5.8 & 0.3 & 0.8 & 7 & 10 & 3 & 0.9 \\
\hline 4 & 15 & 30 & 15 & 5.8 & 2 & 0.05 & 7 & 10 & 3 & 0.2 \\
\hline 5 & 15 & 25 & 28 & 3 & 2 & 0.8 & 7 & 25 & 3 & 0.7 \\
\hline 6 & 15 & 25 & 28 & 5.8 & 0.3 & 0.05 & 4 & 25 & 5 & 0.7 \\
\hline 7 & 100 & 25 & 15 & 3 & 2 & 0.05 & 7 & 25 & 5 & 1.1 \\
\hline 8 & 100 & 30 & 28 & 3 & 0.3 & 0.05 & 7 & 10 & 3 & 0.8 \\
\hline 9 & 100 & 30 & 15 & 3 & 0.3 & 0.8 & 4 & 25 & 3 & 1.4 \\
\hline 10 & 15 & 30 & 15 & 5.8 & 0.3 & 0.8 & 7 & 25 & 5 & 0.7 \\
\hline 11 & 100 & 25 & 15 & 5.8 & 2 & 0.8 & 4 & 10 & 5 & 0.8 \\
\hline 12 & 15 & 25 & 15 & 3 & 0.3 & 0.05 & 4 & 10 & 5 & 0.2 \\
\hline
\end{tabular}

Table 5 : ANOVAfor Central Composite Design

\begin{tabular}{|c|c|c|c|c|c|c|}
\hline Source & SS & df & MS & F Value & $P$ - value Prob $>F$ & \\
\hline Model & 0.872372 & 14 & 0.062312 & 15.24563 & $<0.0001$ & Significant \\
\hline A & 0.136504 & 1 & 0.136504 & 33.39778 & $<0.0001$ & \\
\hline B & 0.078204 & 1 & 0.078204 & 19.13382 & 0.0005 & \\
\hline $\mathrm{H}$ & 0.009204 & 1 & 0.009204 & 2.251937 & 0.1542 & \\
\hline J & 0.024704 & 1 & 0.024704 & 6.044244 & 0.1266 & \\
\hline$A B$ & 0.008556 & 1 & 0.008556 & 2.093414 & 0.0216 & \\
\hline $\mathrm{AH}$ & 0.006806 & 1 & 0.006806 & 1.665251 & 0.2164 & \\
\hline AJ & 0.163423 & 1 & 0.033306 & 8.148872 & 0.0311 & \\
\hline BA & 0.567831 & 1 & 0.567831 & 0.013762 & 0.9082 & \\
\hline $\mathrm{BH}$ & 0.112446 & 1 & 0.009506 & 2.325846 & 0.0142 & \\
\hline BJ & 0.021756 & 1 & 0.021756 & 5.322992 & 0.1957 & \\
\hline$A^{2}$ & 0.226824 & 1 & 0.226824 & 55.49591 & $<0.0001$ & \\
\hline$B^{2}$ & 0.233103 & 1 & 0.233103 & 57.03205 & $<0.0001$ & \\
\hline $\mathrm{H}^{2}$ & 0.168753 & 1 & 0.168753 & 41.28786 & $<0.0001$ & \\
\hline $\mathrm{J}^{2}$ & 0.142931 & 1 & 0.142931 & 34.97027 & $<0.0001$ & \\
\hline Residual & 0.061308 & 15 & 0.004087 & & & \\
\hline Lack of fit & 0.050158 & 10 & 0.005016 & 2.249253 & 0.1920 & Non-significant \\
\hline Pure error & 0.01115 & 5 & 0.00223 & & & \\
\hline Cor Total & 0.93368 & 29 & U & & & \\
\hline
\end{tabular}

Where, $\mathrm{SS}=$ Sum of Square; $\mathrm{df}=$ degrees of freedom; MS = Mean Square

ferrous sulfate heptahydrate and calcium chloride at a high level (coded +1 ) and low level (coded -1) (Table 1) for lovastatin production. Significant parameters were determined using Design Expert Version 8.0 software with 12 experimental designs (Table 2) (Box and Hunter 1957; Sayyad et al., 2007).

RSM AND Fuzzy inference system: The significant variables screened by PBD were optimized using RSM employing Central Composite Design (CCD). Their possible interaction and optimum operational conditions were analyzed by 25 runs of experiments. Significance of each component was determined by
F-test and P-value. Probability level, $\mathrm{P}<0.05$ was considered to be statistically significant. The significant factors were also analyzed using FLS, where Fuzzy rule viewer constructed the system with 14 set of rules (Gupta et al., 2009) (Table 3) for determining optimum concentration of input variables (A, B, H and $\mathrm{J})$ and output variables (Lovastatin production) (Honda and Kobayashi, 2000). The mamdani fuzzy inference system adjusts the membership functions to control the relation between input and output variables using MATLAB Version 7.3 (Fig. 1). It involves five subsequent steps from fuzzification to defuzzification where the crisp values of input variables $\left(\mathrm{gl}^{-1}\right)$ such 


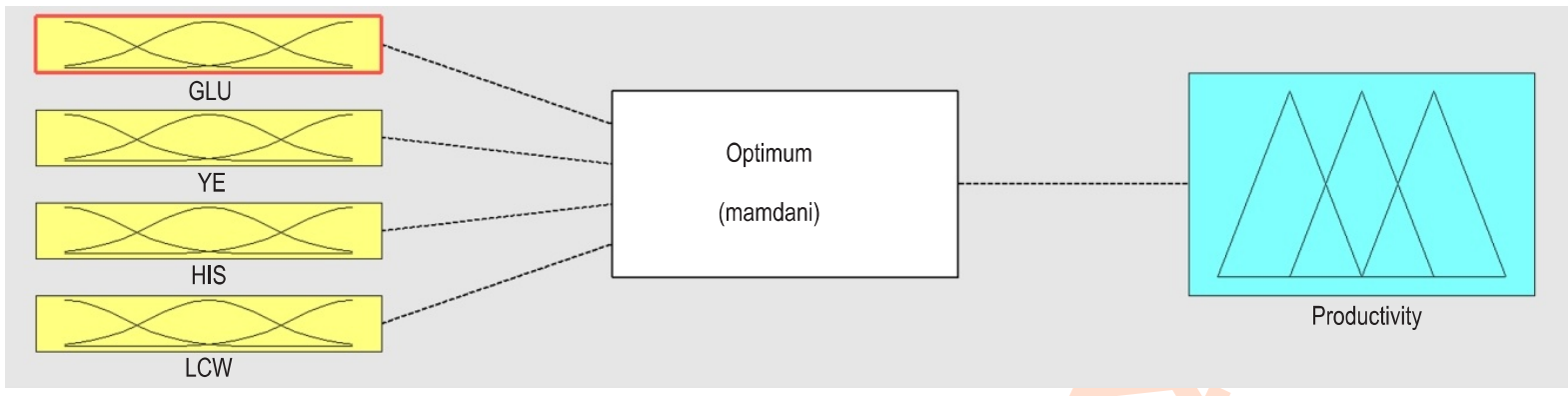

Fig. 1: Fuzzy inference system in MATLAB Software version 7.3 (Where GLU - Glucose, YE - Yeast Extract, HIS - Histidine and LCW - Liquid Cheese Whey).

as glucose (0-100), yeast extract (0-30), histidine (0-7), LCW $(0-$ 25) were fuzzified into degree of membership with respect to fuzzy sets and finally extract a precise quantity out of the range of fuzzy set to output variable (Monton et al., 2013). Accuracy in the prediction of lovastatin yield via RSM and Fuzzy logic system was compared.

\section{Results and Discussion}

$F$. nectrioides was isolated and its sequence was submitted in National Center for Biotechnology Information (NCBI) with accession number MH173849 (Fig. 2). The presence of lovastatin in the fermentation broth was confirmed using HPLC with silica gel (60-120 mesh size) as a stationary phase in the column $(300 \mathrm{~mm} \times 18 \mathrm{~mm})$. Retention time of fermentation broth was $5.047 \mathrm{~min}$, which was almost close to the retention time of

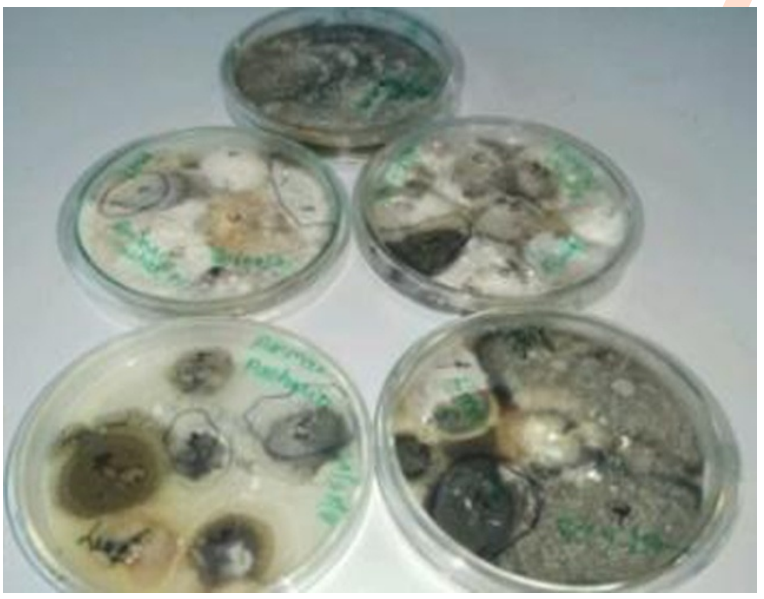

Endophytic fungi propagules emerging from $E$. hirta standard lovastatin (5.124 min) (Fig 3a, b). Increase in lovastatin production was then analyzed further using RSM and FLS. Experiments conducted through PBD screened the media components, $A$ to I and indicated that glucose $(A)$, yeast extract $(B)$, histidine $(\mathrm{H})$ and liquid cheese whey $(\mathrm{J})$ were most significant variables. The positive and negative effects of the media components are represented graphically in Pareto chart (Fig. 4) and their experimental yield is listed in Table 4.

The effect of these four significant variables $A, B, H$ and $J$ on the lovastatin production was studied by RSM. To optimize the actual concentrations, CCD preceded further with 25 runs of experiments. All the experiments were done in $250 \mathrm{ml}$ Erlenmeyer flask containing $30 \mathrm{ml}$ of media. The results were further analyzed statistically and interpreted with analysis of variance (ANOVA) in Table 5. Arulmathi and Elangovan (2016) reported that F- test with

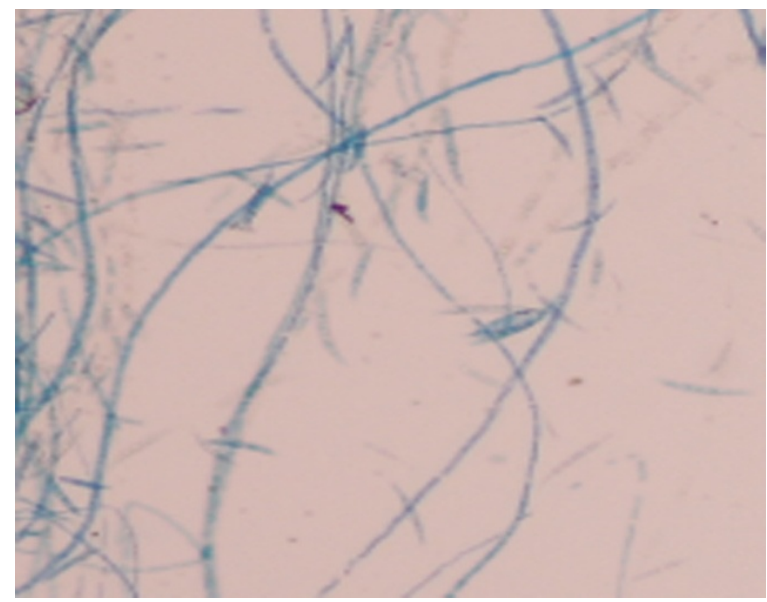

F. nectrioides

Fig. 2 : Propagation and microscopic images of F. nectrioides (MH173849) from E. hirta. 

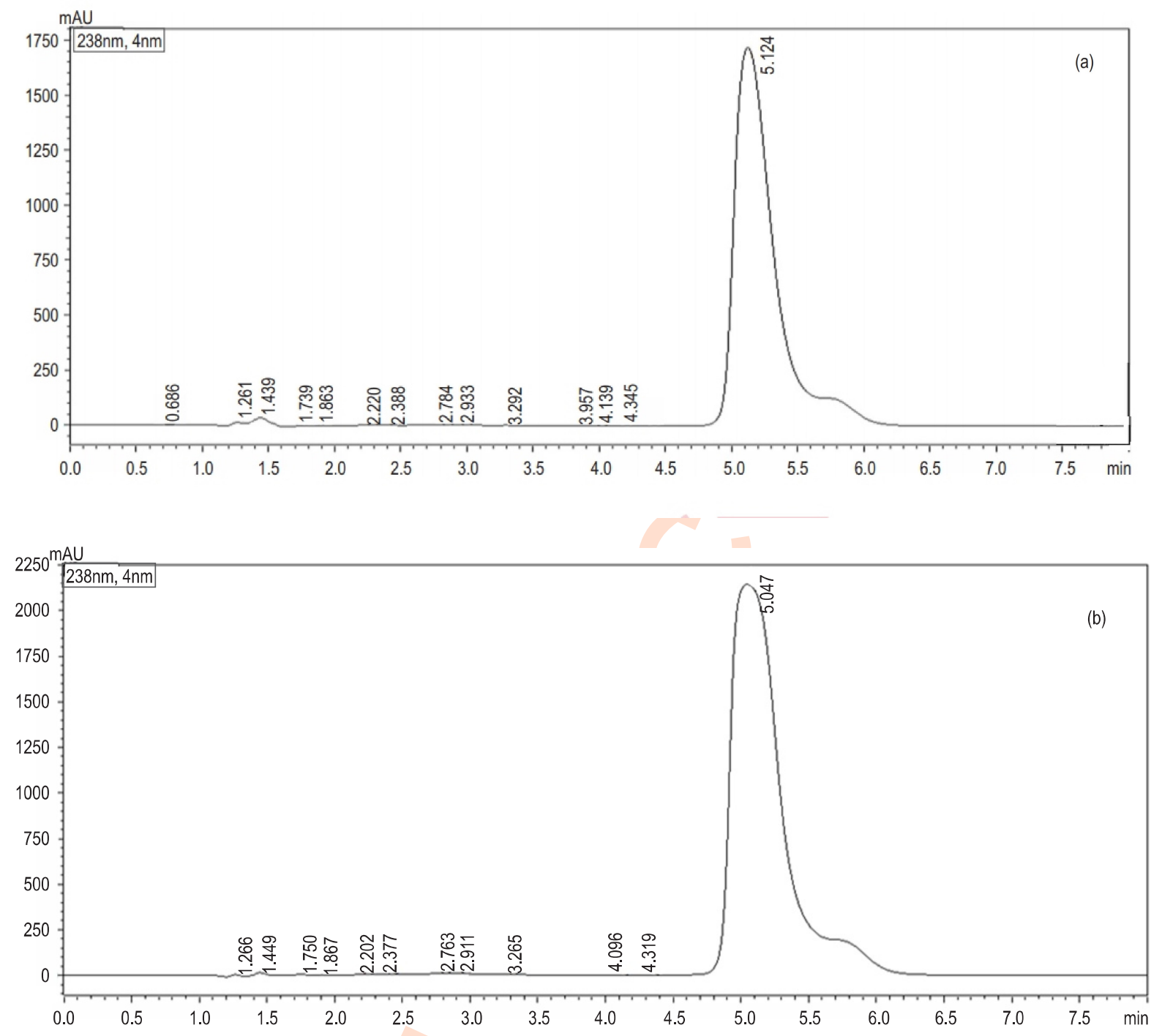

Fig. 3 : HPLC chromatogram showing peaks of (a) standard lovastatin and (b) lovastatin produced by F. nectrioides.

a very low probability revealed high significance for the regression model. The model F-value of 15.24 implies that the model was significant (Table 5) and there was only $0.01 \%$ chance that a "Model F-Value" could occur due to noise. Values of "Prob > $\mathrm{F}$ "less than 0.0500 indicate that the model terms were significant. Luthra et al. (2015) also reported similar results. In this case glucose, yeast extract, histidine and liquid cheese whey were significant model terms where values greater than 0.1000 indicate that the model terms were not significant as reported by Pansuriya and Singhal (2010). The "Lack of fit F-value" of 2.24 implies that the curvature (as measured by difference between the average of the center points and the average of the factorial points) in the design space was not significant relative to noise. The R-square value and "AdjR-Square" value of this model was 0.9905 and 0.9479 , which were higher than the reported values of Mouafi et al. (2016). Adequate precision measures the signal to noise ratio. This model can be used to navigate the design space. The optimum level of variables and interaction effects were found by 3D contour plots (Fig. 5) as mentioned by Luthra et al. (2015).

Graphical representation of response surface and contour plots determine the interaction effects of four significant factors on the response. Each of the actual response was compared with the predicted value. The predicted and the 
Design-Expert ${ }^{\circledR S}$ Software Ln (Yield)

A: Glucose

B: Yeast extract

C: Peptonized milk

D: Soya flour

E: Potassium Di hydrogen Phosphate

$F$ : Magnesium sulphate

G: Ferrous sulphate heptahydrate (Dv1)

$\mathrm{H}$ : Histidine

I: Calcium chloride (Dv2)

$\mathrm{J}$ : Liquid cheese whey

$\mathrm{K}$ : Corn steep liquor

a Possitive effects

- Negative effects

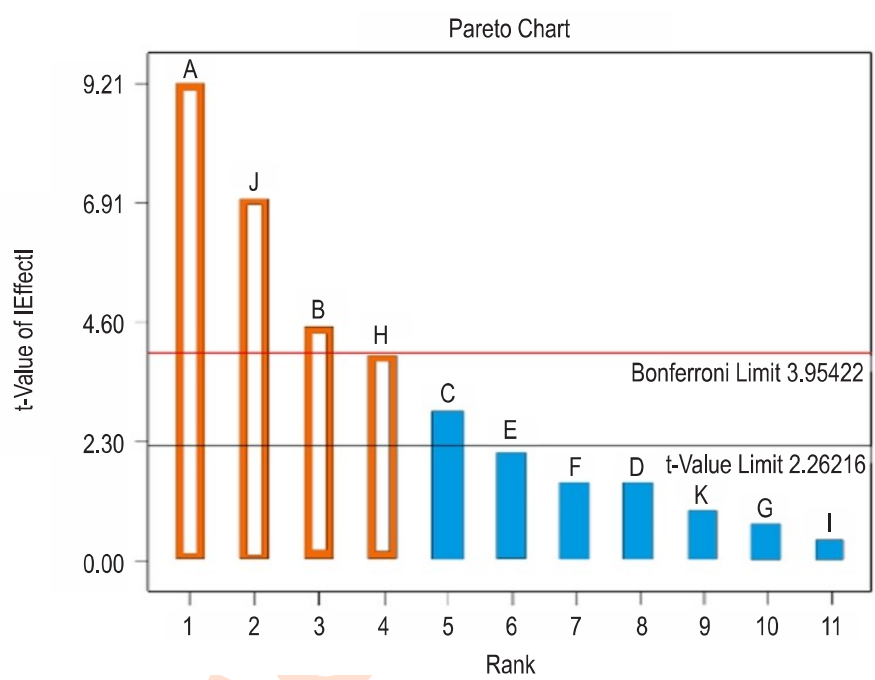

Fig. 4 : Pareto chart for positive and negative effects of variables in PBD.
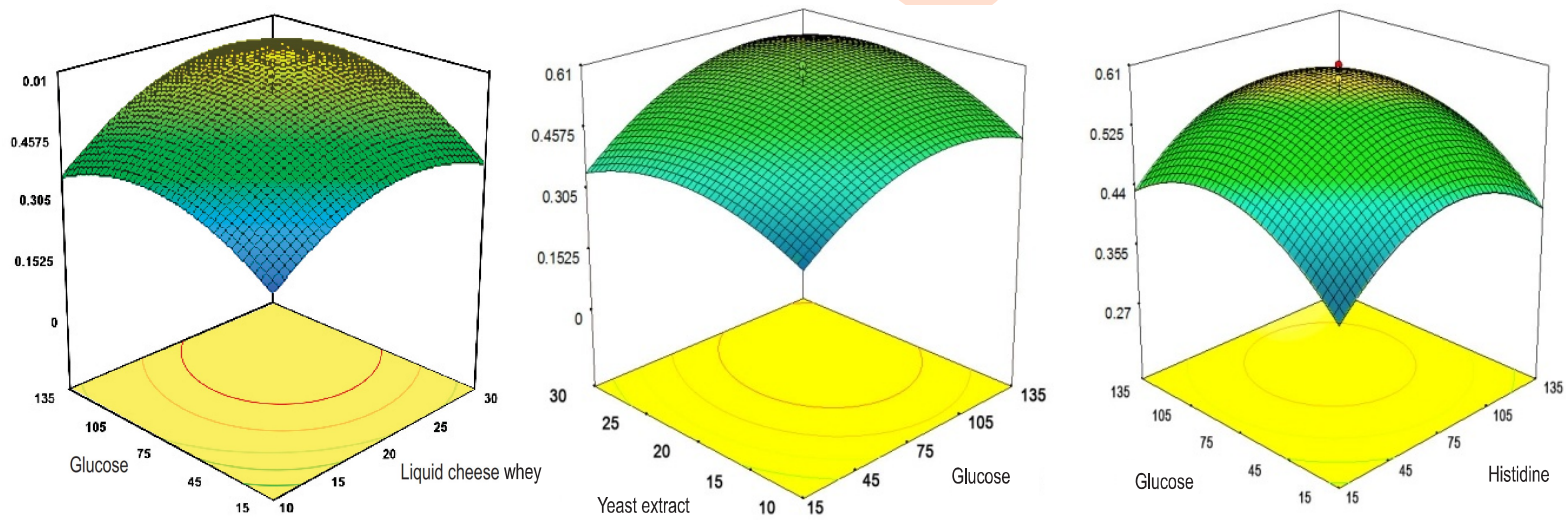

Fig. 5:3D surface and contour plots for optimum lovastatin production.

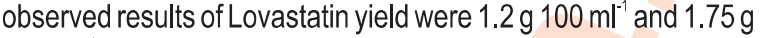
$100 \mathrm{ml}^{-1}$, whereas Karthika et al. (2013) reported the predicted

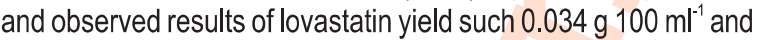

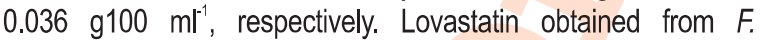
nectrioides (MH173849) isolate had a good model fit due to high value of $R^{2}$. Thus, optimization of significant media components increased the lovastatin production by F. nectrioides (MH173849).

The polynomial equation derived from multiple regression analysis is as follows:

Lovastatin Yield $(Y)=0.575+0.075417^{*}$ Glucose+ $0.057083^{*}$ Yeastextract $+0.019583^{*}$ Histidine $+0.032083^{*}$ Liquid cheese whey+ $0.023125^{*}$ Glucose* Yeast extract+ $0.045625^{*}$ Glucose* Histidine+ $0.020625^{*}$ Glucose* Liquid cheese whey+ $0.024375^{\star}$ Yeast extract* Histidine $+0.036875^{*}$ Yeast extract ${ }^{*}$
Liquid cheese whey+ $0.001875^{*}$ Histidine* Liquid cheese whey-

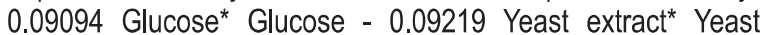
extract- 0.07844 Histidine* Histidine -0.07219 Liquid cheese whey* Liquid cheese whey. Ozlem et al. (2015) reported that Fuzzy rule viewer with different set of rules provided crispy output for the numerical range of input variables as that of our output (Fig. 6). Surface plot for the effect of significant factors on lovastatin production was constructed (Fig. 7, b) and is represented in Table 6. MATLAB ingrained fuzzy rule based system predicted the best combination and interaction of input variables and their predicted yield was compared with the theoretical yield. The surface plot of FLS between liquid cheese whey and glucose produced maximum lovastatin of $1.8 \mathrm{~g}^{100 \mathrm{ml}^{-1}}$

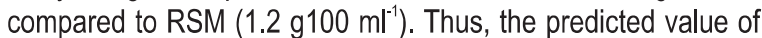
lovastatin productivity by means of liquid cheese whey and glucose was found maximum and closer to the theoretical value 


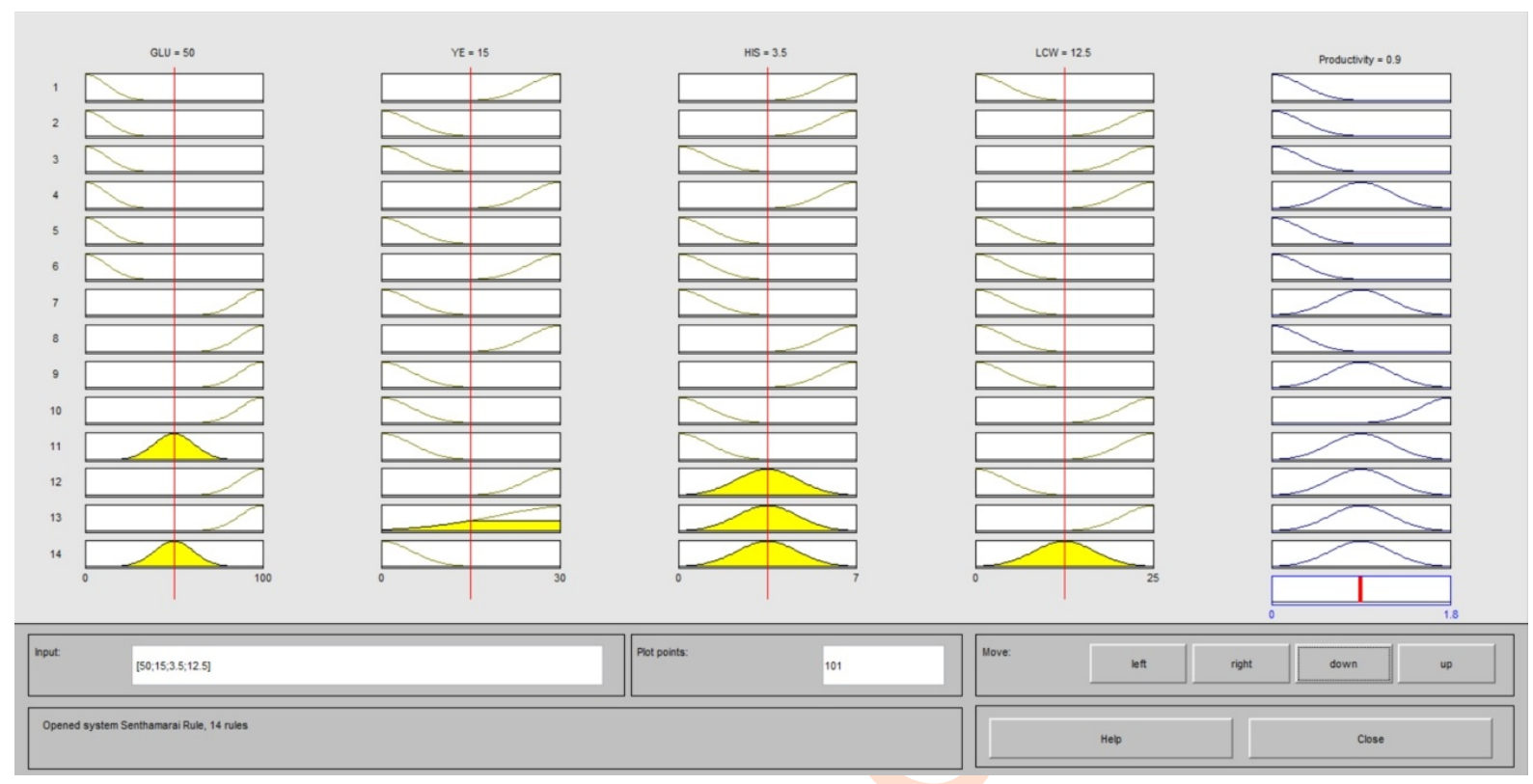

Fig. 6 : Fuzzy rule viewer for lovastatin production.
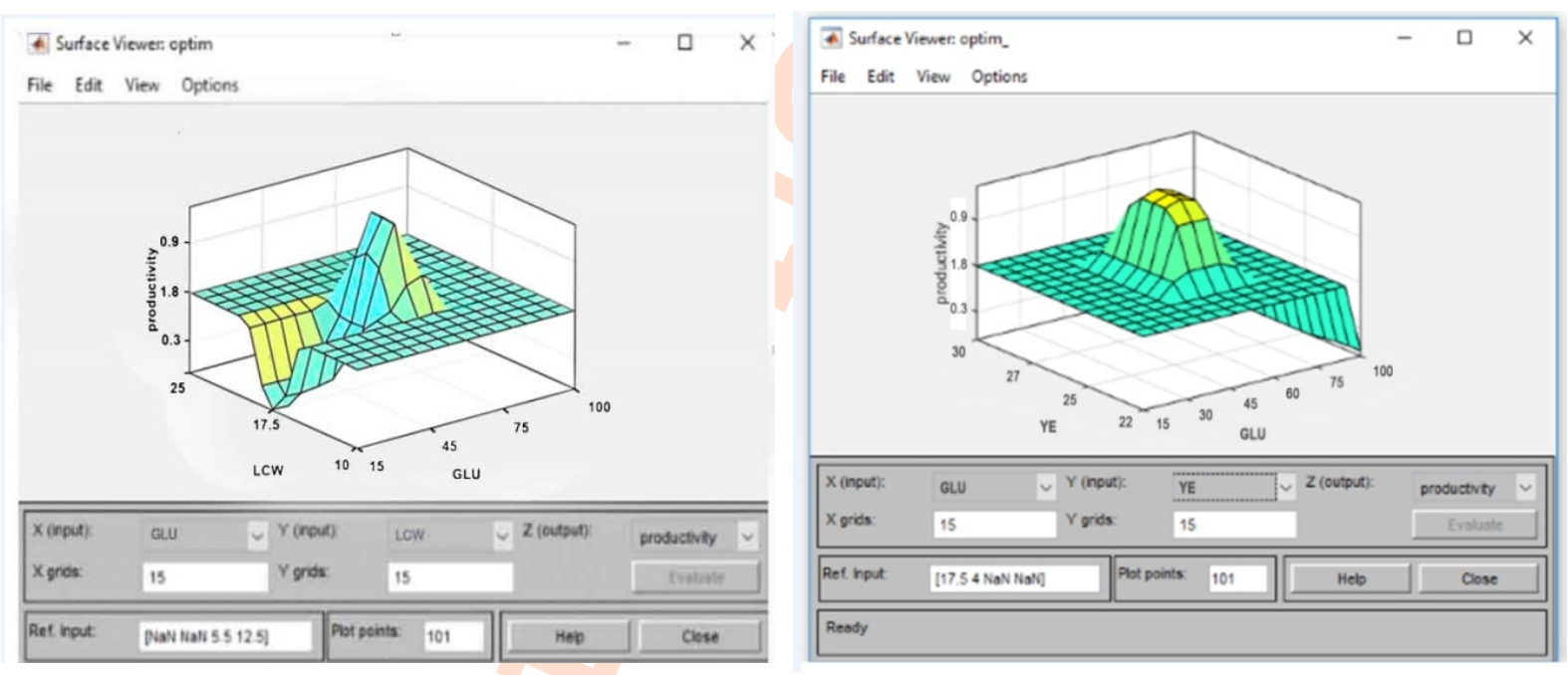

Fig. 7 : Surface plot demonstration on lovastatin yield due to the effect of (a) Liquid Cheese Whey and Glucose; (b) Yeast extract and Glucose.

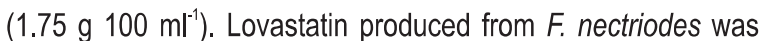
higher than those reported from Aspergillus terreus and Rhizopus oryzae (Rajkumar et al., 2018). Hence, from this investigation it was concluded that a novel strategy was adopted to enhance lovastatin production by new isolate, F. nectriodes utilizing industrial waste such as liquid cheese whey, as a cheap carbon source, with different combination of glucose, histidine and yeast extract. This is the first report to use liquid cheese whey and $F$. nectriodes for enhanced lovastatin production. RSM and Fuzzy models were utilized and, thus, the more accurate prediction was achieved by FUZZY models compared to RSM models.

\section{Acknowledgments}

The authors are thankful to the Chairman, Trustee, Principal and supervisor of Bannari Amman Institute of Technology, 
Sathyamangalam, Erode District for providing all the necessary facilities and encouragement. Special thanks to Dr. A.K.S. Rawat, National Botanical Research Institute, Lucknow and Dr. Sogra FBA, Post-doctoral research associate, Texas A\&M University for their constant guidance

\section{References}

Arulmathi, P. and G. Elangovan: Applications of response surface methodology and artificial neural network for decolorization of distillery spent wash by using activated Piper nigrum. J. Environ. Biol., 37, 1225-1263 (2016).

Boruta, T. and M. Bizukojc: Production of lovastatin and itaconic acid by Aspergillus terreus: A comparative perspective. World J. Microbiol. Biotechnol., 33, 1-12 (2017)

Box, G.E.P. and J.S. Hunter: Multifactor experimental design for exploring response surfaces. Ann. Math. Stat., 28, 195-241 (1957).

Casas López, J.L., J.A. Sánchez Pérez, J.M. Fernández Sevilla, F.G. Acién Fernández, E. Molina Grima, Y. Chisti and M. Bizukojc: Production of lovastatin by Aspergillus terreus: Effects of the $\mathrm{C}: \mathrm{N}$ ratio and the principal nutrients on growth and metabolite production. Enzyme. Microb. Technol., 33, 270-277 (2003).

Davies, J.T., S. F. Delfino, C.E. Feinberg, M.F. Johnson, V.L. Nappi, J. T. Olinger, A.P. Schwab and H.I. Swanson: Current and emerging uses of statins in clinical therapeutics : A review. Lipid. Insights, $\mathbf{9}$, 13-29 (2016)

Davignon, J. and L.A. Leiter: Ongoing clinical trials of the pleiotropic effects of statins. Vasc. Hlth. Risk. Manag., 1, $29-40$ (2005).

Dhar, R. and V.K. Nigam: Studies on process parameters for production of lovastatin. Asian. J. Biomed. Pharm. Sci., 5, 25-30 (2015).

Dobranic, J. K., J.A. Johnson and Q. R. Alikhan: Isolation of endophytic fungi from eastern larch (Larix laricina) leaves from New Brunswick. Can. J. Microbiol., 41, 194-198 (1995).

Friedrich, J., M. Zuzek, M. Bencina, A. Cimerman, A. Strancar and I. Radez: High-performance liquid chromatographic analysis of mevinolin as mevinolinic acid in fermentation broths. J. Chromatogr. A., 704, 363-367 (1995).

Gonciarz, J., A. Kowalska and M. Bizukojc: Application of microparticleenhanced cultivation to increase the access of oxygen to Aspergillus terreus ATCC 20542 mycelium and intensify lovastatin biosynthesis in batch and continuous fed-batch stirred tank bioreactors. Biochem. Eng. J., 109, 178-188 (2016).

Goswami, S., A.S. Vidyarthi, B. Bhunia and T. Mandal: A review on lovastatin and its production. J. Biochem. Tech., 4, 581-58 (2012).

Gupta, K., B. Maiti, P.K. Mishra and P. Srivastava: Fuzzy rule-based prediction of lovastatin productivity in continuous mode using pellets of Aspergillus terreus in an airlift reactor. J. Biochem. Tech., 2, 138-143 (2009).

Hajjaj, H., P. Niederberger and P. Duboc : Lovastatin biosynthesis by Aspergillus terreus in a chemically defined medium. Appl. Environ. Microbiol., 67, 2596-2602 (2001).

Honda, H. and T. Kobayashi: Fuzzy control of bioprocess in Japan. Biotechnol. Annu. Rev., 5,1-23 (2000).

Hutchinson, C.R., J. Kennedy, C. Park, S. Kendrew, K. Auclair and J. Vederas: Aspects of the biosynthesis of non-aromatic fungal polyketides by iterative polyketide synthases. Antonie. Van. Leeuwenhoek, 78, 287-295(2000).

Karthika, C., G. Sharmila, C. Muthukumaran and M. Krishnan : Utilization of whey powder as an alternate carbon source for production of hypocholesterolemic drug by Aspergillus terreus MTCC 1281. Food. Sci. Biotechnol., 22, 1-7 (2013).

Kysilka, R. and V. Kren : Determination of lovastatin (mevinolin) and mevinolinic acid in fermentation liquids. J. Chromatogr., 630, 415 417 (1993).

Lievore, P., D.R. Simões, K. M. Silva, N. L. Drunkler, A. C. Barana, A. Nogueira and I.M. Demiate: Chemical characterization and application of acid whey in fermented milk. J. Food Sci. Technol,, 52, 2083-2092 (2015)

Luthra, U., N. Singh, A. Tripathi, S. Vora and V. Bhosle: Media Optimization for lovastatin production by statistical approach using Aspergillus terreus by submerged fermentation. Int. J. Res. Med. Sci., 2, 4520-4528 (2015).

Monton, S., P. Unrean, J. Pimsamarn, P. Kitsubun and A. Tongta : Fuzzy logic control of rotating drum bioreactor for improved production of amylase and protease enzymes by Aspergillus oryzae in solidstate fermentation. J. Microbiol. Biotechnol., 23, 335-342 (2013).

Mouafi, F.E., G.S. Ibrahim and M.M. Abo Elsoud: Optimization of lovastatin production from Aspergillus fumigatus. Genet. Eng. Biotechnol. J., 14,1-7(2016)

Ozlem, T. and G. Nevin : Comparison of fuzzy logic based models for the multi-response surface problems with replicated response measures. Appl. Soft. Comput., 37, 887-896 (2015).

Pahan, K.: Lipid-lowering drugs. Cell. Mol. Life. Sci., 63, 1165-1178 (2006).

Pansuriya, R.C. and R. S. Singhal : Response surface methodology for optimization of production of lovastatin by solid state fermentation. Braz. J. Microbiol., 41, 164-172 (2010).

Plackett, R.L. and J.P. Burman: The design of optimum multifactorial experiments. Biometrika, 33, 305-325(1946)

Pinruan, U., N. Rungjindamai, R. Choeyklin, S. Lumyong, K. D. Hyde and E. B. G. Jones: Occurrence and diversity of basidiomycetous endophytes from the oil palm, Elaeis guineensis in Thailand. Fungal. Divers., 41, 71-88 (2010).

Rajkumar Immanuel S. and P. Anusha : Production of lovastatin by soil microfungi Rhizopus oryzae. Acta. Sci. Medica. Sci., 3, 70-74 (2018).

Samiee, S.M., N. Moazami, S. Haghighi, F.A. Mohseni, S. Mirdamadi and M.R.Bakhtiari : Screening of lovastatin production by filamentous fungi. Iran Biomed J., 7, 29-33 (2003).

Sayyad, S. A., B.P. Panda, S. Javed and M. Ali: Optimization of nutrient parameters for lovastatin production by Monascus purpureus MTCC 369 under submerged fermentation using response surface methodology. Appl. Microbiol. Biotechnol., 73, 1054-1058 (2007).

Seenivasan, A., S. Subhagar, R. Aravindan and T. Viruthagiri : Microbial production and biomedical applications of lovastatin. Indian J. Pharm. Sci., 70, 701-709 (2008).

Su, Y.C., J.J. Wang, T.T. Lin and T.M. Pan: Production of secondary metabolites, $\mathrm{y}$-amino butyric acid and monacolin $\mathrm{K}$ by Monascus. J. Ind. Microbiol. Biotechnol., 30, 41-46 (2003).

Tandon,V., G. Bano, V. Khajuria, A. Parihar and S.Gupta: Pleiotropic effects of statins. Ind. J. Pharmacol., 37, 77-85(2005).

Wang, Y.N., R.Wang, R. W.Li and C.Y.Tang : Whey recovery using forward osmosis-Evaluating the factors limiting the flux performance. J. Membr. Sci., 533, 179-189 (2017).

White, T.J., T. Bruns, S. Lee and J. Taylor: Amplification and direct sequencing of fungal ribosomal RNA genes for phylogenetics in PCR Protocols: A guide to methods and applications. Academic. Press, 1, 315-322 (1990). 